\title{
Characterizing pedagogical practices of university physics students in informal learning environments
}

\author{
Kathleen A. Hinko* \\ JILA AMO Physics Frontier Center and the Department of Physics, \\ University of Colorado Boulder, Boulder, Colorado 80309, USA \\ Peter Madigan, Eric Miller, and Noah D. Finkelstein \\ Department of Physics, University of Colorado Boulder, Boulder, Colorado 80309, USA
}

(Received 1 December 2014; published 22 February 2016)

\begin{abstract}
[This paper is part of the Focused Collection on Preparing and Supporting University Physics Educators.] University educators (UEs) have a long history of teaching physics not only in formal classroom settings but also in informal outreach environments. The pedagogical practices of UEs in informal physics teaching have not been widely studied, and they may provide insight into formal practices and preparation. We investigate the interactions between UEs and children in an afterschool physics program facilitated by university physics students from the University of Colorado Boulder. In this program, physics undergraduates, graduate students, and postdoctoral researchers work with K-8 children on hands-on physics activities on a weekly basis over the course of a semester. We use an activity theoretic framework as a tool to examine situational aspects of individuals' behavior in the complex structure of the afterschool program. Using this framework, we analyze video of UE-child interactions and identify three main pedagogical modalities that UEs display during activities: instruction, consultation, and participation modes. These modes are characterized by certain language, physical location, and objectives that establish differences in UE-child roles and division of labor. Based on this analysis, we discuss implications for promoting pedagogical strategies through purposeful curriculum development and university educator preparation.
\end{abstract}

DOI: 10.1103/PhysRevPhysEducRes.12.010111

\section{INTRODUCTION}

Traditionally, physicists have been introduced to formal teaching roles as graduate student teaching assistants (TAs) [1] and, more recently, as undergraduate learning assistants (LAs) [2]. Physics, however, also has a long tradition of facilitating informal educational activities to engage external groups in the community through "outreach" [3]. The outcomes of these outreach events are frequently measured in terms of the impact on the public [4,5]. These informal learning environments, however, can be designed to prepare and support the university participants' pedagogical development [6,7]. Framed this way, these experiences can be a significant part of the professional development of physics students and faculty.

\section{A. Informal environments for teaching and learning physics}

Informal environments offer unique and rich opportunities for participants to engage in teaching and learning.

\footnotetext{
*kathleen.hinko@colorado.edu

Published by the American Physical Society under the terms of the Creative Commons Attribution 3.0 License. Further distribution of this work must maintain attribution to the author $(s)$ and the published article's title, journal citation, and DOI.
}

Informal learning differs from formal learning by occurring outside of normal school time, as well as in a variety of other ways. For instance, informal environments are distinct from formal learning settings as they are often low stakes and low threshold for participants, including facilitators and children. Informal learning environments can often align with inquiry or practice-based content, as they operate outside of traditional school norms for behavior and are exempt from curricular pressures associated with highstakes testing, now so pervasive in K-12 education. Goals for learners in informal environments can be content related, such as demonstrating conceptual understanding and process skills, as well as affective and identity related, such as promoting enthusiasm for science and the development of science identity [8].

Informal science programming, or as it is often called in a university setting, outreach, is engaged in by a vast majority of physics departments in the U.S. The American Physical Society includes public outreach as part of its mission [9], emphasizing that informal programming is inherent to the work of practicing physicists. Goals of informal physics programs are to increase the number of students from underrepresented groups majoring in science, technology, engineering, and mathematics (STEM) fields and to improve the scientific literacy of the general population $[8,10]$. The motivating factors for university 
students and scientists to facilitate these programs have been studied $[11,12]$ and include the following: serving the local community, fulfilling grant requirements, recruiting students to the physics department, and gaining teaching experience. Little research has been done, however, on whether and how these experiences impact teaching mastery. Additionally, while informal programming is prevalent throughout the physics community, it can vary widely in terms of audience, content, duration, presentation style, facilitation, and institutional support, including the roles that university students play in the programming. Programs range from one-time events to intensive summer camps, span the age range from grades K-12 to adult, and in many cases are facilitated by undergraduate and graduate students along with faculty and staff. Examples of informal physics programs specifically facilitated by university students include the Physics Van at the University of Illinois Urbana-Champaign [13], Little Shop of Physics at Colorado State University [14], the Physics Circus at the University of Texas [15], and many others. At the University of Colorado Boulder, the Partnerships for Informal Science Education in the Community (PISEC) afterschool program seeks to engage local K-8 children from underrepresented populations in hands-on physics activities [16]. Simultaneously, PISEC seeks to build an identity in its university participants that embraces informal education and diversity as part of the culture of physics.

\section{B. Pedagogical practices of university educators (UEs)}

As this PRST-PER Focused Collection highlights, the development of undergraduate and graduate students as teachers and as scientists is an important endeavor of universities and physics departments. One may typically think of physics professors gaining their teaching training in the formal setting of the college classroom, with their first experiences as TAs or LAs. An overlooked area of physics teaching experience for undergraduate and graduate physics students, however, is informal settings, where these students often serve as facilitators. The importance of including university students in facilitating informal STEM programs has been described by Leshner [17]. He has made the case to include training in STEM outreach as part of the graduate student experience. Additionally, calls to train university STEM students in communicating science to the public are widespread [18].

Characterizing the pedagogical practices of teachers in K-12 and college classrooms has been a priority for researchers seeking to determine how best to support teachers (and students) in creating productive learning environments [19]. For example, interactive teaching techniques used in physics courses have been shown to improve student performance on standardized concept inventories $[20,21]$. Implications from these and a wide variety of studies have led university instructors to adopt clicker questions [22], Peer Instruction [23], Tutorials [24], and other interactive techniques [21] as part of their formal classroom teaching practice. Further, educator-student interactions have been studied in formal settings through a variety of means. Observational protocols $[25,26]$ have been used to characterize interactive engagement in classrooms, discerning between more "teacher-centered" or "student-centered" approaches [27]. Shulman has identified pedagogical content knowledge as essential to effective teaching for a specific content area [28]. Researchers have looked at the pedagogical practices of university students who teach in formal settings, such as with undergraduates in elementary school classrooms [29] and with graduate students as part of the national science foundation GK-12 program [30]. They have found gains for university students in terms of motivation, content knowledge, and understanding of pedagogy.

While pedagogical approaches have been investigated in the context of formal classroom learning environments, less attention has been paid to those who teach in informal settings, especially from a discipline-based perspective. Findings from formal learning environments may be limited: informal settings are often very dynamic, and there are inherently different constraints in terms of teacherto-student ratio, content coverage, and goals for students. This work establishes a framework for studying pedagogical strategies of university educators (UEs) in informal settings. We investigate the interactions between adults and children in the PISEC afterschool physics program, where university physics volunteers (including undergraduate students, graduate students, and postdoctoral researchers) work with small groups of children on hands-on, exploratory activities for 8-10 weeks over the course of the semester. Building on calls for enhancing opportunities for physics undergraduate and graduate students to engage in educational practices (including this journal, PhysTEC [31], and APLU's Science and Math Teaching Imperative [32]), we explore the potential of informal learning environments to provide such opportunities [16,33]. As part of our larger effort to characterize participant experiences in these informal environments, in the current work, we investigate the following research question: What are the different forms of interaction between university educators and children in our physics afterschool program? Based on our findings, we discuss the factors that influence UE teaching strategies and student responses in this environment as well as the implications for the preparation and support of UEs in both formal and informal settings.

\section{STUDY CONTEXT}

\section{A. PISEC afterschool program}

The PISEC program is based on the successful Fifth Dimension (5D) afterschool programming model developed by Cole and colleagues, which originally focused on 
increasing computer, math, and linguistic literacy [34]. The 5D model is structured around several main goals derived from sociocultural approaches to teaching and learning. The first goal is to provide a rich, educational experience for children after school. The second is to make use of technologies in order to encourage children's participation, especially children from groups traditionally underrepresented and underresourced in our educational system. Another aim is to bring together children and adults from diverse groups to perform activities in a way that makes use of and is enhanced by the diversity of the participants. In this way, the 5D model seeks to benefit the university educators as well as the children.

As a university-run, physics-focused informal program, however, we have additional goals for afterschool programming. We seek to enculturate children, especially those from underrepresented groups, into the community of physicists as a way to provide access to scientific careers, increase scientific literacy, and make physics and physicists less intimidating and more accessible. In concert with this goal, we strive to provide an environment where children and adults can be engaged together in authentic physics practice. Distinct from much of school-based physics, authentic physics practice includes exploration, creativity, collaboration, and practices in line with the nature of science, such as prediction, measurement, model making, and evidence-based reasoning [35].

These intertwined sets of goals are realized in the PISEC afterschool program, where educational opportunities in physics are provided for students in grades K-8 from underrepresented groups. An essential and somewhat unique feature of the PISEC instantiation of the 5D model is the role of discipline-based educators (those with physics content expertise). The afterschool activities are facilitated by undergraduate and graduate students as well as postdoctoral researchers from the University of Colorado (CU) Boulder Physics Department and the JILA AMO Physics Frontier Center [36], as well as an occasional individual from a related STEM field, such as engineering. The format of PISEC consists of weekly, 60-min sessions that continue over the course of 8-10 weeks each academic semester. Typically, 20-30 children and 6-8 UEs meet each week for an hour after school at a site (either a school or community center). Each semester there are 3-5 distinct PISEC sites that each have a different set of UEs; thus, in total, there are 25-30 UEs who participate each semester as well as approximately 100 children. At the start of each session, the participants break into small groups of 2-4 children and one UE who work together on physics activities. The activities are exploratory and encourage children to construct scientific knowledge based on experiments, observations, and argumentation $[37,38]$. Either the PISEC director (the first author) or an experienced site leader also attends each session: They are responsible for helping activities run smoothly, dealing with minor behavioral issues among the children, bringing notebooks and supplies, and providing transportation to and from the site.

\section{B. Physics undergraduate and graduate students' role as afterschool educators}

In their role as university educators, physics undergraduate and graduate students are provided with a unique teaching opportunity that is relatively low risk to themselves; for example, compared to a TA position, there is not a lengthy time commitment or grading, and they receive support and resources from the program director and site leaders. Additionally, UEs are able to make meaningful connections with children and communities that they may not interact with in their physics studies and research.

We observe several key features, as well as limitations, that come with disciplinary-based UE involvement. Undergraduate and graduate physics student participants in PISEC are entrenched in a disciplinary identity and are at various stages in their academic preparation. Since UEs have significant knowledge of physics, explicit descriptions of content in the written prompts to UEs and children can be reduced. In this way, UEs are able to co-construct specific approaches to the curriculum with the children and utilize the wide variety of other PISEC structures, such as the group collectively determining how to test air resistance. The activity prompts are able to be short, open ended. and emphasize exploration, eliminating any resemblance to "cookbook" laboratory exercises or worksheets that children may have experienced in formal learning environments. Because of this structure, UEs are able to bring in the culture of physics to the PISEC environment by focusing on the elements of exploration and the nature of science. For example, an activity prompt such as "How does a parachute work? What will I test?" allows children and UEs to determine their own meaning of "works" and "test." The use of disciplinary experts ensures the outcomes are scientifically normative as well as relevant to the children who co-construct the definitions. The activity may start with group discussion about which variables are relevant to the phenomenon and what options for measurement are appropriate. Then the group may investigate the variety of available equipment associated with the activity, including toy parachutes of different sizes and materials, potential components for parachute onstruction (tissue paper, plastic bags, string, etc.), as well as the other equipment from the full suite of activities. Thus, children and UEs are able to engage in play and creativity, troubleshoot experiments, test their ideas, and construct arguments based on evidence from measurements [39].

One limitation to disciplinary personnel facilitating design-based programming with children is a lack of pedagogical expertise. While UEs are asked to model and assist children in the processes and habits of the mind of a physicist, they are sometimes stymied when addressing children's prior conceptions, affective responses, and level 
of familiarity with physics jargon. We take a holistic view in the design and study of UE-children interactions, not only in preparing UEs but also in constructing an environment to promote productive forms of interaction. For the explicit preparation of UEs, they complete on average five hours of training prior to the 8-10 contact hours they have with children at the site. This preparation includes an information session on the structure and format of the program and time for conducting the hands-on science activities that are brought to the site. Participants are encouraged to work together and to provide feedback on all aspects of the activities. University volunteers also attend a workshop on pedagogy and diversity. During the workshop, university participants are presented with scenarios that may arise during the course of working with children and are asked to consider possible responses. For example, they discuss what approaches to take when a student does not draw the physically correct conclusion from an experiment. They are encouraged to take on the role of a coach or mentor, privileging children's ideas and explanations over a "correct" understanding of physics concepts. Another tactic UEs are suggested to use is answering children's questions with questions of their own, such as "How do you think it works?" and "How could we try your idea?". In this way, we try to minimize the potential for UEs or children to treat scientific knowledge as a fully formed product of adulthood or to regard the UEs as gatekeepers of this knowledge. There is also a component of the preparation centered on communication skills, where UEs practice communicating about physics topics in everyday language and receive feedback as to the appropriateness of their analogies, language, and representations [40].

Not only do UEs have formal preparation, but they also participate in social structures that support collaborative, practice-based learning. Throughout the semester and typically during travel to and from the site, UEs take part in frequent discussions with each other and the program director about the weekly PISEC sessions. These informal conversations allow UEs to reflect and share their experiences working with children. Topics include issues related to pedagogical and pedagogical content knowledge, student affect and engagement, and classroom management techniques.

\section{APPLYING AN ACTIVITY THEORETIC FRAMEWORK}

Because the UEs and children engage in a consistent and relatively structured environment, activity theory (AT) provides a productive lens from which we might characterize the outcomes from the complex interactions among the UEs, children, curricula, and environment in which the PISEC activities occur [41]. Activity theory derives from earlier work of Vygotsky [39] and others [42,43], building on the notion of higher-order human cognition as mediated by tools and artifacts in cultural contexts. Activity theory advances this earlier work by taking a systems or holistic approach, expanding the basic unit of analysis from an individual engaged in mediated action to include the broader interplay of the individual with the situated contexts [44] —in our case to learning environments. As with other theoretical frameworks that are included in sociocultural historical activity theories [41], higher-order cognition is taken as the mediated process of engaging in the world. The mediation occurs through essential, culturally bound tools: students use language and other human-constructed artifacts (math, lasers, measurement systems, etc.) as they learn about given concepts (electromagnetic radiation, gravity, etc.). As such, the primary unit of analysis in our studies is the activity system, which includes the individual students and educators, their goals, the tools they use, as well as essential elements of the situated environment, such as other members of the community, established norms, and expected roles. In recent years, the PER community has increasingly drawn from AT as a framework for analyzing the complex and integrated nature of our educational environments $[45,46]$. For a more detailed review of AT and the broader suite of sociocultural historical activity theories, Cole [41] and Daniels et al. [47] are good sources.

Figure 1 (from Engestrom [48]) shows an AT triangle where the lines represent the interconnected elements that form the activity system. The subjects and objects (or objectives) of the activity system create the dynamic interplay that is central to AT analysis [49]. While both the subject and object can influence other aspects of the activity system, the subject is unique due to its needs and actions. In this work, our focus is on the UE and his or her pedagogical moves, so we treat the UE as the subject. (Children can also be the subject and will likely have different objectives-in AT they would be represented as an overlapping or intersecting activity system.) Mediational means allow the subject to interact with the object of the activity system. The mediational means can be either concrete or abstract tools, for example, a hammer or a mnemonic. The use of these mediating artifacts can be limited or enhanced by the experience and knowledge of the subject and can also influence the three other aspects of

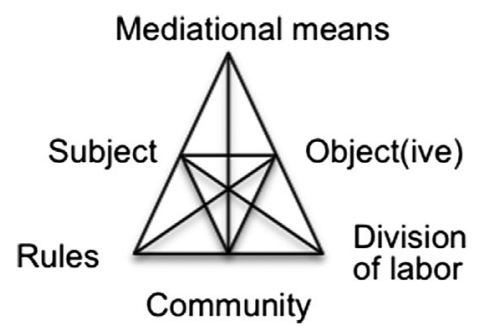

FIG. 1. A generalized activity theoretic triangle [48], which we use as the fundamental unit of analysis for UE-child interactions at PISEC. Lines indicate connections between categories. 
the activity system - the rules, the community, and the division of labor. These aspects begin to include social dynamics into the activity. The rules of the activity control how the subject can interact with the other influences of the system, which can be either implicit or explicit norms of interaction. Community situates the activity system within a broader social structure with a shared objective and influences the development of the activity's other aspects. And finally, the division of labor differentiates the activity of multiple subjects interacting with the same object.

We use activity theory as a tool to examine situational aspects of individuals' behaviors in the local context of our afterschool environment. This work focuses primarily on identifying the components of the system within the AT framework. In this way, if one element of the activity system is changed - for example, the object-we are able to identify changes in other elements that characterize the nature of the group interaction. From our analysis with AT, we characterize three distinct modalities of UE and child interactions, which shape and are shaped by their situated contexts. Details of our analysis protocol are given in the following section.

\section{STUDY METHODS}

In order to study the interactions between children and UEs doing physics activities, we collected video data during PISEC sessions [Institutional Review Board (IRB) Protocol 13-0528]. Data were collected at two of four sites during the fall 2013 semester: one middle school (grades 6-8) and one K-8 school that had children from grades 4 to 8 participating in the program. During this semester, the physics activities focused on optics, including concepts and phenomena related to lenses, reflection, and refraction. Four video cameras were set up around the periphery of the room during each afterschool session in which children were involved in hands-on physics activities. These cameras were zoomed-in on individual groups of participants. Groups were selected for observation each week based on several factors. We attempted to record each UE and each child at least once during the semester, so often we would select different groups each week to record. Sometimes groups would choose to work on activities outside of the classroom, which prevented us from obtaining video. We also wanted to capture the dynamics between participants, so we would typically not record groups when they were working on computer activities as interactions between UEs and children were more limited. Audio recorders were placed on the work tables of groups corresponding to the video cameras to ensure better sound quality. The first week and the last two weeks of the program were not recorded since hands-on physics activities were not conducted during these sessions (during the first week, the facilitators led introductions and performed demonstrations, and during the last two weeks, children made stop-action-motion movies summarizing their activities). Additionally, out of the possible weeks that were available, logistical circumstances (cancellation due to snow, camera malfunction) prevented a few sessions from being recorded or recorded with all four cameras. Thus, five weeks of activities were recorded for the middle school site and three weeks of activities were recorded for the K-8 school site, resulting in a total of $25 \mathrm{~h}$ of video and audio. The content of the video varies-sometimes groups move out of the frame for stretches of time or the camera is accidentally moved and then no longer faces the group. Furthermore, the members of each group are not always constant from week to week, due to absences by either children or UEs, which can result in new arrangements of the groups.

The purpose and context of the video for the children was couched within an existing construct of the program called "Mission Control." Children in PISEC are told that a group of physicists at the University of Colorado known as Mission Control are responsible for providing the curriculum, thus passing authority to a third party and allowing for collusion between UEs and children [34]. Children document their activities in a personal scientific notebook; notebooks are collected and taken back the university where Mission Control writes supportive comments before the next session. As evidenced by frequent comments directed at Mission Control in their notebooks, students see this entity as a helpful and fun aspect of the program. In terms of the video, children are told that Mission Control is very interested in how science is done during PISEC and that they can choose to be recorded as part of a Mission Control research study with no effect on their participation in the program. They are also told they are allowed to use the cameras to make their own videos when they are near the end of doing an activity. Students show high levels of enthusiasm at being recorded and using the video equipment themselves, sometimes speaking directly to Mission Control in the cameras or audio recorders.

After data were collected, the video and audio recordings were synchronized for editing, which significantly improved the audio quality and permitted easier transcription. Recordings were scanned for "rich" segments with clear interaction between UEs and students and discernible audio and video. Interactions are defined here as periods of time when UEs and students are engaged in scientific activity, including activity selection, experimentation, discussion, and documentation. Segments selected for analysis were between 3 and 5 min in length. Sections of "poor" quality video that were not included in the analysis had indistinguishable audio, participants located out of frame, participants blocking the camera, or the camera being moved.

Starting from an initial focus on "student vs teachercenteredness" [27], we analyzed video segments (12 segments, representing six UEs) using an AT framework as a checklist to see if interactions would fall into these two categories. In particular, the verbal and body language, physical handling of materials, and physical position of 
group members were used to define an activity system for these interactions. From our AT analysis, however, we found that the dichotomy of teacher and student centeredness was insufficient to categorize the complex patterns in UE-student interactions. By grouping interactions with similar AT elements, three categories of interactions emerged that were dependent on UE pedagogical moves during scientific activity with the students, termed instruction, consultation, and participation modes. The AT analyses of the video segments were completed by two of authors; the subsequent modality categorization was discussed by those two and a third one of authors, and consensus on categorization was reached. The characteristics of the emergent categories were presented along with video data to a variety of experts for feedback, after which the definitive features of the categories were further refined. The additional one of authors who had not participated in the prior analysis was then given a description of the defining characteristics of these modes and "blindly" reanalyzed the video segments using this categorization as a framework. This researcher's analyses (specifically, the labeling of UE modality in each interaction) agreed with the previous analyses and acted as an interrater reliability check for the modality characterization and the findings on modal consistency in Sec. VII. Finally, video of the full data set of all UE-student interactions (33 activities ranging from 5 to $30 \mathrm{~min}$ in length, $10 \mathrm{UEs}$ ) were categorized based on the emergent modality framework.

\section{CHARACTERIZING PEDAGOGICAL MODES IN PISEC}

From our analysis, we find that UEs interact with children in three main pedagogical modalities: instruction, consultation, or participation modes. In this section, we define each mode by specific characteristics that are the evident from our application of an activity theoretic lens to the collected data. We also present specific examples as evidence of the different modalities (associated video clips are in Supplemental Material [50]).

\section{A. Instruction mode}

The characteristics of instruction mode are similar to those of a traditional, teacher-centered classroom setting. A UE in instruction mode exerts a sizable influence over students' interactions with the experiment, often leading students step by step through an activity. In this way, the UE's moves position him or her as a scientific authority. While students may make observations and construct arguments based on their observations, the UE typically oversees the activity and approves the students' experimental setup, activity, observations, and conclusions. If students are proceeding with the activity in a manner that seems unproductive or they are drawing physically incorrect conclusions, the UE will stop that line of activity and redirect the students towards a more acceptable way of approaching the activity. The UE also maintains control of the apparatus, by demonstrating how to use it or by passing it around. The UE is physically positioned near the students and is the focus of students' attention-students frequently turn their bodies or faces towards the UE. A hallmark of instruction mode is that most questions and comments made by students are directed towards the UE, not to other group members. The UE's response is typically a direct, concrete statement answering the question. Language used by the UE reinforces the position of the UE as an authority figure: for instance, they may ask students to confirm his or her understanding verbally.

In the following example, UE "Michael" exemplifies instruction mode while working with three 6th grade students on an experiment involving a simple optical microscope (Fig. 2). The prompt for this activity asks the group to use the microscope to look at several objects, draw pictures of the objects under the microscope, and discuss how the microscope works. The group spent $30 \mathrm{~min}$ working on this activity. During this time, Michael either places the microscope in front of himself or passes it from student to student. Students have their notebooks open in front of them, and often are poised to write. In the transcript below, Michael is explaining to the students about the different placement of lenses inside the microscope.

Michael: So the second part, the lens-

Student 1: Oh! Sometimes if you put it too far or to close, you cannot see.

Michael: So we have one lens in there, right? Each lens makes like a different distance. Does that make sense? Student 2: You-

Michael: [interrupts] So say my lens is here [indicates location with hand], if I have a really, really strong lens, maybe I'm down here [moves a piece of paper far below hand]; if I have a really, really weak lens, maybe I'm up here [moves paper nearer hand]. So each lens [moving the piece of paper up and down] makes a different distance clear. Does that make sense?

Student 1: Oh yeah, like my sister, she's really, she can't really see that much, like she probably couldn't see that earthquake right there [points to a poster across the room].

Michael: Yeah exactly, 'cause that one's too far, it's just the distance that she can't see, right? So let's write it down [thumps finger on table], that's good, that's awesome.

In this scene, Michael uses moves that clearly demonstrate instruction mode. He speaks at length about the apparatus, describing its functionality with words and gestures. His words are almost entirely explanatory-the only questions he asks of the students are an effort to gauge their understanding of his explanation ("So we have one 


\section{Instruction Mode}
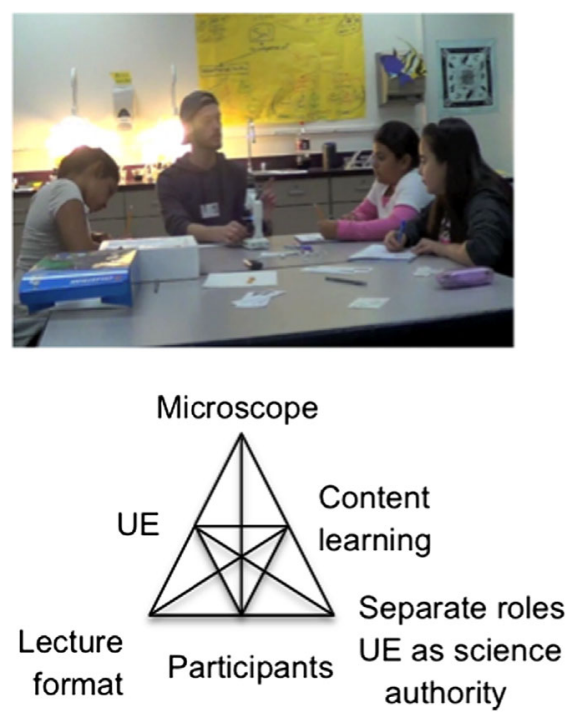

FIG. 2. Instruction mode. Photo (top) shows Michael and his student group working on a microscope activity during a PISEC session. The triangle (bottom) shows the interconnected aspects of the activity system where Michael is the subject.

lens in there, right?," "Does that make sense?"). He sits centrally in the group, and for most of the activity all of the students' shoulders are facing him. Students are engaged throughout the activity, and spend time writing in their notebooks. When students volunteer information they speak to Michael directly, while other group members listen. During his explanation, Michael uses scientific language that is appropriate for the grade level of the students and the qualitative nature of the activity. For example, he refrains from using terms such as "focal length" and chooses instead a simpler phrasing: "each lens makes a different length." In his instructorlike role, Michael also provides positive affirmation to the students, supplying confirmation and praise of their interpretation of his explanation ("Yeah, exactly... that's good, that's awesome"). As shown in this example, Instruction mode is teacher centered and heavily guided, with students and UEs in separate roles during the activity.

\section{B. Consultation mode}

Consultation mode is the most prevalent mode that we see UEs engage in during PISEC (see Sec. VII). Unlike instruction mode, UEs do not give direct explanations but instead make comments and suggestions on students' activity, acting as more of an advisor to the group. Students have control of the equipment most of the time, and they interact mainly with each other while manipulating the equipment and discussing their experiments. They turn to the UE to ask for advice on procedure and assistance with troubleshooting, to demonstrate part of the activity, and to share enthusiasm about their results or the aesthetic appeal of certain physical phenomena. The UE often interjects in the form of probing questions, such as "What do you think will happen?" or "How do you think it works?". Their frequent use of the pronoun "you" situates themselves as separate from the main activity of the students. In consultation mode, the UE usually stands above the group or sits just outside of the group circle, but may crouch or kneel to students' eye level when engaging with them. The students' focus is most often on their own experiment or peers' experiments; though they may look at a UE when the UE offers advice, all of the students' shoulders are rarely turned towards the UE at the same time.

In the following excerpt, the UE "Jorge" is working in a group of four 5th grade students on an experiment using colored filters and flashlights (Fig. 3). The prompt for the activity suggests placing the filters over the flashlight in different combinations to make colored light. While working on this activity, the students sit around a table, sharing flashlights and many plastic filters. There are several instances where one student will hold the flashlight and other students will hold up filters to the light. Students speak with each other regularly about the colors they have made. Frequently, an individual student will share his or her procedure (such as combining two specific colors) with the other group members, and the other students will reproduce the procedure themselves. Jorge walks around the outside of the group, interjecting periodically and also responding to students, as in the example below.

Student 1: We made turquoise!

Jorge: Turquoise? How?

Student 2: It's 'cause we overlapped the blue [with itself] and it turned into turquoise. [Students continue to explore]

Student 2: [combining filters] It makes yellow! Sorta like yellow-y green.

Student 3: Hehe!

Jorge: Look at $[\ldots]$ try closing your eyes and $[\ldots]$ what do you see?

Student 1: I'm gonna try to overlap it.

Jorge: Yeah, try to overlap it.

Student 2: So when it's like this [holds red filter to eyes], it's red and when it's like this [folds filter], it's more red. Jorge: It is [nodding and smiling].

Student 2: So that's how we got turquoise, we overlapped the blue, err, the green and the blue.

Here, Jorge exemplifies consultation mode. He stands off to the side of the group, suggests avenues of inquiry, and shows his approval when the students come to a result independently. Unlike instruction mode, though, these moves are in response to, and not leading, the student activity; the students remain the primary agents. When the students approach Jorge with their findings, he asks about 


\section{Consultation Mode}

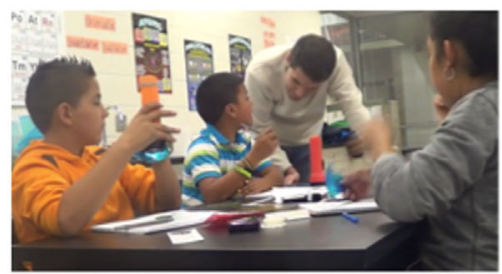

Flashlights and colored filters

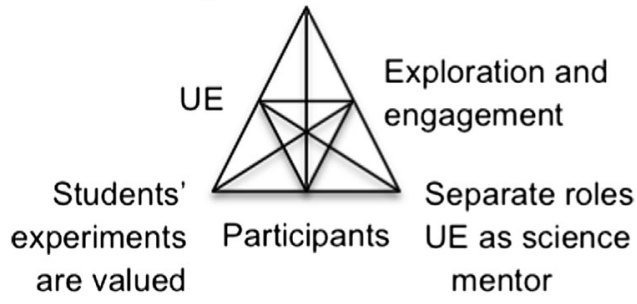

FIG. 3. Consultation mode. Photo (top) shows Jorge and his group working on an activity to make colored light with flashlights and filters. The triangle (bottom) shows the interconnected aspects of the system with Jorge as the subject.

their methods, allowing them to reflect upon the experiment. Students share excitement with Jorge about their scientific discoveries ("We made turquoise!"). The groups language reflects the separate roles when talking to Jorge: students use the pronoun "we" to describe their activity and Jorge uses "you" when asking the students questions. Jorge does not correct the students when they make an incorrect statement (overlapping blue with itself does not create turquoise), which indicates that Jorge is focused more on students' exploration rather than on their obtaining a correct result.

\section{Participation mode}

Participation mode is exemplified by a UE working as part of the team of students on the activity, taking on the role of group member more so than group leader (instruction mode) or group advisor (consultation mode). In this mode, both UEs and students manipulate equipment and make measurements. The UE is physically positioned within the group, for instance, sitting at the table with the students. Comments or questions spoken by both the UE and the students are phrased in terms of the group, often using first person plural pronouns, such as "What should we do?" or "Let's try this." The UE may share his or her knowledge by modeling the experiment, as opposed to giving an explanation. For example, a UE might manipulate equipment to achieve some result, and then students may replicate or make a variation on the UE's actions. A UE in participation mode embodies an approach of "show, don't tell" more so than any of the other modes of interaction.

The following excerpt is from UE "Mateo" and three 4th grade students working on an extension of an activity that prompts students to examine a mirror by holding it in
Participation Mode

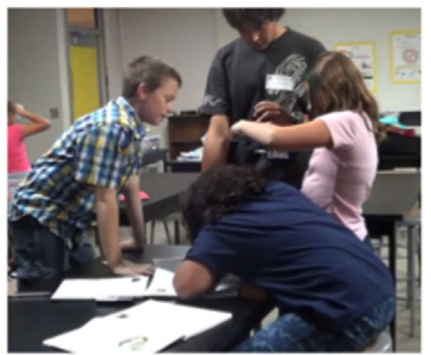

Mirrors and flashlight

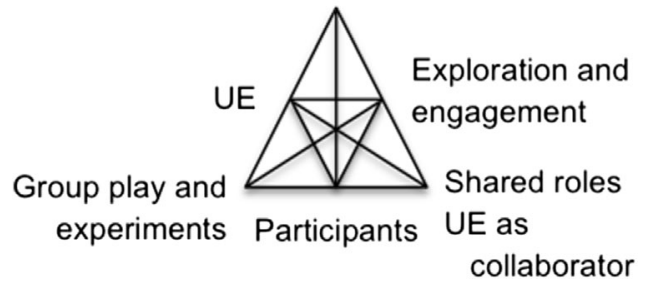

FIG. 4. Participation mode. Photo (top) shows Mateo interacting with students in his group during PISEC. They are working on an activity reflecting light off of mirrors. The triangle (bottom) shows the interconnected aspects of the system with Mateo as the subject.

various positions (close to and far from face, at angles to head, etc.) and observing what can be seen in the mirror (Fig. 4). The students have obtained a flashlight from the equipment box and are shining it at the mirrors. At this point, Mateo is holding two mirrors while Student 1 stands next to him directing the flashlight at the mirrors. The other students are closely watching the position of the light from different vantage points.

Student 1: You may have to keep the mirror higher. I thought that people were [going to turn off] the [overhead] lights? Whaaat? [Sees the light reflected onto the ceiling] Whaaat!?

Mateo: Oh, oh, hey, hey. Right there, right there! Ahh ahh ahh! You see it? You see it!? It's right there! [Students 2 and 3 move closer] Oh, right there. Now what happens if we put this one here?

Student 2: It's on me!

Mateo: It's on you [moves mirror] now it's on-

Student 3: Me!

Mateo: Now it's on you!

As seen in the figure, Mateo is engaged and participating in the experiment. He is physically positioned within the group of students and is directly manipulating the equipment not as the experimental authority, but as a group member. Student 1 tells Mateo where to hold the mirrorshis directions to him indicate his participatory moves are recognized by the students; he is treated as part of the group, not someone removed from the activity. Mateo shows excitement at the outcomes of the activity, and he 
TABLE I. Activity theoretic comparison of pedagogical modes.

\begin{tabular}{|c|c|c|c|}
\hline & Instruction & Consultation & Participation \\
\hline Subject & UE & UE & UE \\
\hline Object & $\begin{array}{l}\text { Conveying physics knowledge to } \\
\text { students. }\end{array}$ & $\begin{array}{l}\text { Allowing students to come to an } \\
\text { understanding of the material and } \\
\text { develop independent reasoning } \\
\text { skills. }\end{array}$ & $\begin{array}{l}\text { Sharing in the activity so as } \\
\text { to engage students. }\end{array}$ \\
\hline Rules & $\begin{array}{l}\text { UE talks, students listen and follow } \\
\text { instructions from UE and activity } \\
\text { prompts. Curriculum and UE } \\
\text { guide activity. }\end{array}$ & $\begin{array}{l}\text { UE responds to students' explicit (or } \\
\text { implicit) questions. Both UEs and } \\
\text { students follow curricular prompts. }\end{array}$ & $\begin{array}{l}\text { Experiment and observations } \\
\text { determines outcomes or answers. } \\
\text { All participants ask and answer } \\
\text { questions. Joint construction of } \\
\text { activity by UEs and students. }\end{array}$ \\
\hline Community & Students and UEs. & Students and UEs. & Students and UEs. \\
\hline $\begin{array}{l}\text { Division of } \\
\text { labor }\end{array}$ & $\begin{array}{l}\text { Students conduct experiments. UE } \\
\text { acts as authority figure, gives } \\
\text { directions, and answers questions } \\
\text { explicitly. Students write in } \\
\text { notebooks. }\end{array}$ & $\begin{array}{l}\text { Students conduct experiments. UE } \\
\text { observes and responds to } \\
\text { difficulties or questions, knowing } \\
\text { answer and outcomes. Students } \\
\text { write in notebooks. }\end{array}$ & $\begin{array}{l}\text { Students and UEs collaborate, sharing } \\
\text { responsibility for conducting } \\
\text { experiments. UE models } \\
\text { equipment use. Students write in } \\
\text { notebooks. }\end{array}$ \\
\hline $\begin{array}{l}\text { Mediational } \\
\text { means }\end{array}$ & $\begin{array}{l}\text { Formal physics understanding is } \\
\text { privileged. UE directs use of } \\
\text { experiment and curriculum in the } \\
\text { activity. }\end{array}$ & $\begin{array}{l}\text { Both experiment and curriculum } \\
\text { shape the activity. Emphasis can be } \\
\text { on exploration or goal-oriented } \\
\text { experimentation. }\end{array}$ & $\begin{array}{l}\text { Experiment and physical apparatus } \\
\text { are major meditational elements of } \\
\text { the activity, while curriculum and } \\
\text { formal physics are less significant. }\end{array}$ \\
\hline
\end{tabular}

verbally includes himself in the group's actions ("Now what happens if we put this one there?"). Since all members are part of the exploration, the students and Mateo collaborate on goals and actions for the activity.

\section{COMPARISON OF UE MODES}

From the AT analysis of UE-student interactions, we find generalized characteristics of the different UE pedagogical modalities. Table I compares the AT elements for instruction, consultation, and participation modes. In this environment, different combinations of AT elements characterize the three modalities, and we find elements (rules and division of labor) that help define a mode and elements (object, community, and mediational means) that span the modes. Different combinations of AT elements appear predisposed to different outcomes, but they are not absolute; i.e., it is possible for instruction mode to still support student exploration, but it is less common. The prevalence of modalities across all UEs and the consistency of individual UE modalities are described in Sec. VII.

\section{A. Rules and division of labor define modalities}

Rules and division of labor are dependent on and characterize the UE mode in several ways. Division of labor refers to the observed practices of the individuals within a system to determine the locus of control or power. Rules are the socially constructed moves allowed and sanctioned in an environment. In our analysis we inferred from behavior patterns what the sanctioned moves or "rules" are. While a certain set of rules are shared by all UEs as part of the structure of the program, the "explicit norms and conventions" [41] of interaction within a group vary depending upon the mode. The division of labor is highly dependent upon the UE mode. For example, while the division of labor in participation mode is shared equally throughout all of the group members and the UE, in consultation mode it is divided between the students with the UE as an outside source of knowledge. In instruction mode, the division of labor takes on that of a traditional classroom, in which the students' responsibility is learning, and the UE's responsibility is explicating and ensuring the students understand the material.

One indicator of the rules and division of labor that characterize a modality is the UE and students' body language and how they relate to each other. In instruction mode, the UE is positioned as the head of a group, with the students facing the UE and focusing their attention on the UE. The power structure in this mode is clear: the UE is in charge of teaching the material and the students are in charge of learning. In consultation and participation mode, however, the positioning and body language of the UE disrupt the traditional classroom model by placing the onus of experimentation, as well as both learning and discovery, on the students. In consultation mode, the UE most often stands off to the side while the students interact with each other around a table. A UE in participation mode inserts themselves into the group, by standing or sitting with the other students. 
Another indicator of division of labor and rules is the degree to which UEs speak in an explanatory manner. UEs in instruction mode give the most explanation, UEs in participation mode give the least explanation, and UEs in consultation mode fall somewhere in between. These differences can be seen in how each UE approaches questions from the students. When posed with a question, a UE in instruction mode answers the question directly and explains until he or she feels the student has gained an adequate understanding. In contrast, UEs in consultation mode typically answer questions with leading questions, and will keep asking questions until they feel the student is on the correct track. They refrain from directly answering the initial question but prompt students to come up with their own answer. Finally, UEs in participation mode rarely explain anything directly to the students. Instead, when posed with a question, a UE in participation mode will often manipulate the experiment in a way that reveals a physical property to the students.

\section{B. Community and mediational means span modalities}

In our analysis, we also find AT elements that span the modes. Community is defined by the space, institution, and PISEC structure, which precede the UE and children. For all modes, UEs and children form the community, along with the site leader and school representative. Their roles and division of labor shift but the community is set. In this type of informal environment (with regular, repeated meetings) and most formal environments, the community is similarly set in advance of the educator and students even showing up.

In PISEC, the mediational means include the prompt provided, the experimental materials, student notebooks, and the construct of Mission Control. Of these artifacts, the prompt and materials vary from activity to activity. Prompts list possible materials for use in experimentation and offer a mix of goal- and exploration-oriented tasks. A group can treat the prompt as a list of science goals to achieve, take it only as a starting point for experimentation, or ignore it altogether. There are sometimes constraints on student agency provided by the materials. For some activities, there are enough supplies for each student to have their own setup, while in other activities students must share a single apparatus. Additionally, some experiments may lend themselves to cooperation between students to manipulate the experimental setup, as in the case with flashlights and mirrors described above. Thus, meditational artifacts can be the same across modes (for instance, most groups do the activity with the colored filters), but both who uses them and how they are used (i.e., rules and division of labor) vary by pedagogical mode.

\section{UE objectives}

Activity systems are inherently complex, interwoven structures of exchange among various elements. We find evidence of this complexity in the relationship between the object of the UE and their pedagogical mode. Some objects span pedagogical modes and some vary by pedagogical mode - as do the outcomes that are a product of the UE objective [44]. Here, we show that the different modes of interaction can support varying scientific objectives and student outcomes.

\section{Science objectives}

UEs may have many objectives in their interactions with students, such as making personal connections with their group, having fun, and practicing their teaching skills. We can infer information about the UE's science objectives, or science learning goals for students, from their pedagogical moves - which include (but are not limited to) focusing on accomplishing activity tasks, encouraging free exploration, making scientific measurements, or appropriately using the artifacts provided.

Here, we contrast the different apparent scientific objectives (accomplishing a specific task and engaging in exploration) of two UEs who are both operating in consultation mode. The following example shows UE "Adam" working in a group of two students on an experiment combining different colored filters. This activity is the same one worked on by Jorge and his group, which is described in Sec. V. In the excerpt below, Adam is helping one student to accomplish a goal that is listed as one of the activity prompts: to make white light by combining the colored filters. For several minutes prior this excerpt, Student 1 has struggled to make white light using combinations of only two filters and placing them over the end of the flashlight. Adam has observed this experimentation so far without comment, but then chooses to interject after numerous trials by Student 1 .

Adam: [to Student 1] So do you believe that you can make white and you can't figure it out, or do you believe you can't make white?

Student 1: I'm not really sure. I think one could.

Adam: One could, ok, um... well so...I feel like, then you know there's a combination out there that'll do it, you just have to find it. What are all the colors that you have available to you? Maybe...for simplicity, these are both kinda blue so we'll just use one of them [moving filters], we'll just use that one, and then you've got red. So, what you should make combinations of three out of all of these...I've seen you make-maybe we can do this blue instead of that one [takes away the lighter blue filter].

In this example, the way Adam offers help to Student 1 indicates that Adam is in consultation mode. Even though the student is having difficulty with the activity, Adam does not directly tell the student to combine red, green, and blue 
filters to create white light. Instead, he suggests that the student should try combinations of three instead of two filters. During the activity, Adam sits off to the side at the table, and his interaction with the students is punctuated by periods of independent student work. While he offers suggestions to Student 1 as to how to proceed, the student's focus stays on the experiment.

From this description, it is clear that Adam is in consultation mode; however, his scientific objective and the way it affects his interactions with the group are different from the consultation mode example of Jorge. Jorge's questions and responses to students indicate that he has a goal for students to explore and test possible variations in the activity. Adam is primarily focused on helping his group in the pursuit and achievement of a specific scientific task. These examples illustrate that scientific objectives are not necessarily specific to any individual mode, although it does not indicate that all modes are equally suited to all science objectives.

\section{Student outcomes}

Outcomes like student engagement can be considered a product of the objective-including how students respond and interact with the experiment, the UE, and the rest of the activity system. Based on our analysis of students' affective response (including facial expressions, verbalizations, and body language) and scientific activity, we find that UEs in each modality are able to engage students. Although we may have expected this result for consultation and participation modes, we also see positive student response with UEs in instruction mode. For example, we find that students working with UE Michael (Fig. 2) have high levels of participation: they write lengthy notebook entries, show interest in an activity for extended periods of time, ask frequent questions, and respond enthusiastically to questions asked by Michael. They also express pleasure at seeing Michael by smiling when he joins their group at the beginning of the session and sharing personal stories from school events that day.

Alternatively, we find that although students may be engaged with the activity, they may not demonstrate engagement with the UE, even when the UE is in consultation or participation mode. An example of such student behavior is seen in the following excerpt that follows the UE "Oliver" as he works with two 6th graders. Oliver's suggestions, explanations, and even presence go largely ignored by the students as they manipulate the path of a laser with mirrors. Oliver tries without much success to have them track the laser beam with a piece of paper.

Student 1: Oh, wow. [To Student 2] Dude, it's on your hand.

Student 2: So if I shine it right here-
Oliver: So, are you guys following it with [picks up piece of paper] this one? So you know that it'll go from there, to there, to there. Is that where you wanted it to be? Student 1: [To Student 2] Maybe if we [moves mirror]... Oliver: Oh ok, now it's over here. Alright, 'cause each place you want to catch it so it doesn't go in someone's eye.

Student 1: [to Student 2] Wait, stop. Point that again [uses hand to block beam].

Oliver: [picks up paper again] Here, you can use this. Student 1: [To Student 2, not using paper] Hey, look at this, there's [the beam] over there.

Oliver is another example of consultation mode as evident by his position outside of the group and his offering suggestions as to safe use of the equipment. However, while the students engage with the UE in the consultation cases of Jorge and Adam, Oliver is unable to connect with his students. In this case, the students usually worked with another UE who was absent that day. Oliver was working with them for the first time, which may have contributed to the student response to his pedagogical moves. As such, the student engagement is an outcome that can vary independently from UE mode.

\section{PREVALENCE AND CONSISTENCY OF MODES}

Activity theory can be applied to the UEs over time and in various informal settings in order to characterize trends in UE pedagogical modes. In this section, we present findings from the full data set of the UEs at the two PISEC sites from the fall 2013 semester (described in Sec. IV). We analyzed video of 33 total activities from 6 out of 7 possible UEs from our first site and 4 out of 7 possible UEs from the second site. One UE went to both sites-he was recorded only at the first site. Video of the program director was excluded. We report on two significant findings: prevalence of modes and modal consistency of UEs.

\section{A. Prevalence of modalities}

We categorized the modalities of the UE for each activity in order to determine if one modality was more common among UEs or among types of activities. Figure 5 shows the distribution of UE modalities for the activities that were recorded. We find that consultation mode is the dominant mode for UEs in PISEC. Participation and instruction modes occur 2.5 and 3.5 times less frequently, respectively.

It is likely that a UE's proclivity towards a specific mode is determined by a variety of factors, including UE interpretation of the presite preparation, UE personality and past experience, and the perceived effectiveness of UE moves. The degree to which these factors influence UE mode likely varies from UE to UE, and other factors may influence the mode as well. The presite preparation is 


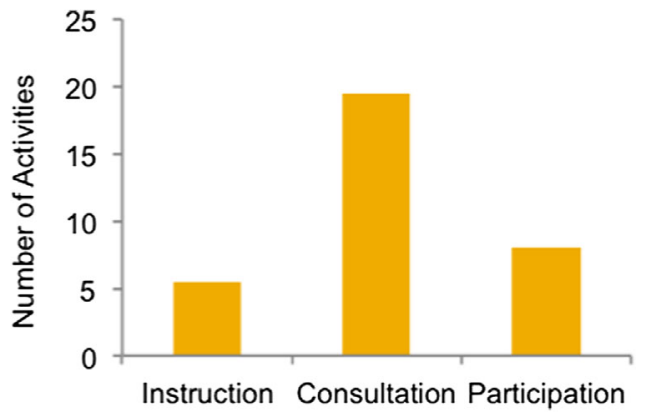

FIG. 5. Prevalence of UE modalities in terms of total number of activities observed $(n=33)$. Consultation mode is observed most frequently, followed by participation and then instruction modes.

perhaps why consultation mode is most strongly represented by the data, and instruction mode most weakly represented, as the preparation espouses a mentoring approach as outlined in Sec. II. As part of the pedagogical workshop, UEs were told to act as a coach or a mentor to the students. They were also told not to instruct the students as they would in a normal classroom setting. It seems likely that as a result of the preparation, some UEs adopted certain moves that characterize consultation mode and suppressed moves that are associated with instruction mode. Participation mode may be influenced both by the preparation and by the nature of the informal setting and the open-ended curriculum prompts. From Fig. 6, we see that instruction mode is demonstrated by UEs who had not previously participated in PISEC, while returning UEs were only in the other two modes; however, more data are necessary in order to establish this connection.

\section{B. Modal consistency of UEs}

While we observe a dominance of the consultation mode, we might anticipate that the UEs demonstrate a range of modalities across activities and over time. It might be hypothesized that simply participating in these rich environments would foster changes in the modalities that UEs

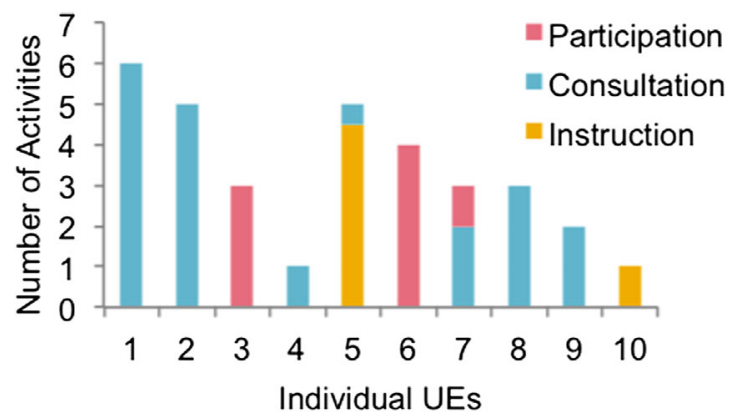

FIG. 6. Modal consistency of UEs. Individual UEs are numbered on the $x$ axis $(n=10)$. UEs $1-4$ were returning volunteers with at least one semester of previous participation. UEs 5-10 were new volunteers. Five of the seven UEs that were recorded for at least three activities are not observed to change modalities, either within an activity or from activity to activity. engage in. While reasonable assumptions, neither outcome appears to be supported in the analysis of UE modalities over activities and over the course of the term. Figure 6 shows the distribution of modality by activity for each of the 10 UEs recorded. Of these 10 UEs, seven UEs were recorded interacting with students during three or more activities. Since the average number of activities completed by each group over the course of the semester was approximately eight, three activities represents more than a third of the total activities worked on by a UE over a semester. Five of these seven UEs stayed in the same mode within every activity. One UE (UE 7) switched from consultation to participation mode for one entire activity. Additionally, from all recorded activities, we observed only one instance of a UE changing modalities during an individual activity (UE 5, from consultation to instruction; each modality is represented by a half activity on the graph). In summary, we find that not only do UEs tend to operate in the same mode between activities, but they also tend to do so from week to week.

A potential reason that UEs' modalities are relatively stable is because once interactions between the students and UE have been established, the rules and division of labor for the group supersede other influences, such as the mediational means. Thus, the components of the activity system reinforce one another in these relationships, and it may be that the initial establishment of a mode informs and impacts future interactions. While we might have originally expected to see changes from instruction to participation mode over time, it is not clear what would be the cause of such a shift. For example, from our data, we find that students can respond with positive affect to UEs in instruction mode. In such a case, the UE might not receive cues that he or she should change to a more participationoriented modality. Furthermore, in this particular instance, it may have been that an instructional mode was most productive towards UE desired outcomes. That said, we do not see UEs varying mode depending upon group or situation-suggesting the objective is comparatively fixed for a UE.

One instance that may push a UE out of their typical mode is variations in attendance by UEs and students. There are sometimes sessions when the number of students exceeds the number of UEs, so that each UE must manage multiple groups of students. This situation can drive UEs into consultation mode even if the UE is normally in participation or instruction mode (as with UE 7), because a UE's time is both divided and limited - consultation mode allows for the most student autonomy, which is necessary if the UE is splitting time between multiple groups.

\section{IMPLICATIONS FOR PREPARING AND SUPPORTING UES}

In this work, we have characterized three pedagogical modalities of UEs in PISEC and described a mechanism 
(AT) for functionally categorizing these different modes. From the application of the emergent modality framework, we have found trends in modal prevalence and consistency. These outcomes suggest a variety of implications for preparing and supporting university physics students as educators, both in PISEC and in the formal educational roles of graduate TAs and undergraduate LAs.

Ultimately, we recommend teaching university educators about these modalities and developing their breadth of skills so that they may make informed decisions about which mode is best to operate in during certain times. In this way, our framework can be used to promote pedagogical flexibility by UEs across the varied physics teaching and learning environments that they may encounter.

\section{A. Implications for PISEC}

As described in Sec. II, our goals for children in PISEC include increasing their familiarity with scientists and scientific careers, encouraging an interest in physics, and providing them with opportunities to engage in authentic physics practices. In our characterization of UE modalities during PISEC, we do not observe a hierarchy of modes that are either "good" or "bad" at achieving these goals. Instead, each modality has both affordances and limitations and may be more or less suitable depending on local circumstances. For instance, in instruction mode, the UE may attend to "content" learning and hence give students welldefined directions, which is a familiar pedagogical move for students in traditional classroom environments and can help them stay on task. Consultation mode can emphasize student-driven, goal-oriented or exploration-oriented science. However, in both instruction and consultation mode, the UE may be seen as a gatekeeper of knowledge, following a set division of labor (UE as expert). Participation mode allows the UE to assume another role and to share his or her interest in physics without claiming scientific authority; however, this approach may not provide students as much autonomy as consultation mode. In summary, we find that UEs in all modes can be effective at interacting with students and obtaining a positive affective response from them, with various objectives and assuming differing roles.

Thus, we suggest that UEs treat these modes as pedagogical tools instead of simply tendencies. In order to encourage UEs in this regard, we need to make these modes salient in UE preparation, that is, to make the roles, rules, and objectives of the activity system explicit. UEs can be made aware of the common modalities, view examples from video, and practice with other UEs during mock interactions. They may then attend to the moves they make while interacting with children at site and monitor their own behavior both in specific activities with children and over time. Reflecting on their practices in field notes and exit surveys may help UEs continue to develop their range of pedagogical skills. Such changes to the PISEC program also hold implications for future studies - we can determine the impact on UEs' attitudes and beliefs about teaching as well as document their actual behavior at site. By including an awareness of pedagogical modes in the toolkit for UEs, we may give them more confidence in their ability to adapt to new situations at PISEC and to be able to work with a range of students' behavior.

\section{B. Implications for TA and LA instructional development}

In our observation of formal preparation of TAs, LAs, and instructors [51], we note that the modalities seem to appear within formal educational contexts as well. Differences between formal and informal settings, as previously described, will impact the characterization as well as the prevalence and consistency of UE pedagogical modality. Notably, the various roles, rules, mediation means, and objectives will vary by environment. For instance, due to the structure of their classroom or curriculum, an instructor might be sequestered to instruction mode (during lecture) or consultation mode (during periods of interactive engagement). A TA or LA, however, may have more fluidity, acting in consultation or participation mode during tutorials, recitations, or in-class discussions. Additionally, office hours, tutoring, and physics help room settings may be an amalgam of informal and formal activities that allows for increased pedagogical flexibility for instructors, TAs, and LAs. The interplay among UE, environment, and pedagogical mode is one that can be discerned by applying the tools of activity theory as described in Table I.

Our data indicate that it may be the default for university educators to stay in the same mode, even as they move across environments and topics. Thus, as with UEs in PISEC, we ought to be explicit about preparing TAs, LAs, and instructors to recognize and act in these different modalities. Without explicit attention to modes, people may take up a mode that is likely influenced by prior beliefs about education, personality, and environmental constraints. We recommend making people aware of these modalities and then practice enacting them during preparation. Awareness may be raised by way of example, such as those instances provided in this paper, which showcase these modalities in action. Practicing the different pedagogical approaches with their peers would be an important exercise before interacting with students. Furthermore, while they are teaching, TAs and LAs could be provided with the framework of modalities and come to conclusions by considering their own behavior, through structured self-reflections or, potentially, video analysis.

This research lays the foundation for rich avenues of future investigation, such as studying the impact of the different modalities on opportunities for children and UEs, 
and how modalities affect various learning outcomes (content, affect, communication, etc.). We also see opportunity to study how we might foster metapedagogical knowledge in university educators across educational environments. Rather than advocating for expertise in a particular pedagogical mode, we anticipate that a facility of working across modalities and knowing when and where to engage in a particular mode will be the essential and preferred outcome.

\section{ACKNOWLEDGMENTS}

The authors want to thank the children and university students in the PISEC program for their participation. We also thank the Physics Education Research group at $\mathrm{CU}$ Boulder for productive discussions and support. This work is funded by the JILA NSF Physics Frontier Center (1125844) and the NSF Advancing Informal STEM Learning Grant (1423496).
[1] E. Etkina, Helping graduate assistants teach physics: Problems and solutions., J. Grad. Teach. Assist. Dev. 7, 123 (2000).

[2] V. Otero, S. Pollock, and N. Finkelstein, A physics department's role in preparing physics teachers: The Colorado Learning Assistant model, Am. J. Phys. 78, 1218 (2010).

[3] American Physical Society Outreach Guide, http://www .aps.org/programs/outreach/guide/.

[4] Afterschool Alliance, http://www.afterschoolalliance.org/ STEM-Afterschool-Outcomes.pdf.

[5] K. Hussar, S. Schwartz, E. Boiselle, and G. Noam, Toward a Systematic Evidence-Base for Science in Out-of-School Time: The Role of Assessment (Harvard University/ McLean Hospital, Boston, 2008).

[6] K. Hinko and N. Finkelstein, in Proceedings of the 2012 Physics Education Research Conference, Philadelphia, PA (AIP, New York, 2012), pp. 178-181.

[7] N. D. Finkelstein and L. M. Mayhew, in Proceedings of the 2008 Physics Education Research Conference, Edmunton, CA (AIP, New York, 2008), pp. 19-22.

[8] National Research Council, Learning Science in Informal Environments: People, Places, and Pursuits (National Academies Press, Washington, DC, 2009).

[9] Education and Outreach Web page of American Physical Society, http://www.aps.org/programs/outreach /initiatives/ index.cfm.

[10] CU Flagship Initiatives, http://www.colorado.edu/ flagship2030/.

[11] E. Andrews, A. Weaver, D. Hanley, J. Shamatha, and G. Melton, Scientists and public outreach: Participation, motivations, and impediments, J. Geosci. Educ. 53, 281 (2005).

[12] A. Skerrett and H. Sevian, Identity and biography as mediators of science and mathematics faculty's involvement in K-12 service, Cult. Stud. Sci. Educ. 5, 743 (2010).

[13] Physics Van, http://van.physics.illinois.edu.

[14] Little Shop of Physics, http://littleshop.physics.colostate .edu.

[15] Physics Circus, http://www.ph.utexas.edu/circus/index.php.

[16] Partnerships for Informal Science Education in the Community, http://www.colorado.edu/physics/PISEC/.

[17] A. Leshner, Outreach training needed, Science 315, 161 (2007).
[18] J. Lubchenco, Entering the century of the environment: A new social contract for science, Science 279, 491 (1997).

[19] N. Kober, Reaching Students: What Research Says About Effective Instruction in Undergraduate Science and Engineering (National Academies Press, Washington, DC, 2015).

[20] R. Hake, Interactive-engagement versus traditional methods: A six-thousand-student survey of mechanics test data for introductory physics courses, Am. J. Phys. 66, 64 (1998).

[21] PhysPort, https://www.physport.org/index.cfm?.

[22] Carl Wieman Science Education Initiative at the University of British Columbia, http://www.cwsei.ubc.ca/resources/ clickers.htm.

[23] C. Crouch, J. Watkins, A. P. Fagen, and E. Mazur, Peer instruction: Engaging students one-on-one, all at once, Research-Based Reform of University Physics 1, 40 (2007).

[24] L. McDermott and P. Shaffer, Tutorials in Introductory Physics (Prentice-Hall, Englewood Cliffs, NJ, 1998).

[25] D. MacIsaac and K. Falconer, Reforming physics education via RTOP, Phys. Teach. 40, 479 (2002).

[26] M. T. Hora, Applying insights from faculty teaching practices to science and math education reforms, WISCAPE Policy Brief, University of WisconsinMadison, Wisconsin Center for the Advancement of Postsecondary Education, 2011; http://ccher.wceruw.org/ documents/WISCAPE\%20Brief\%20from\%20CCHER\% 20Project.pdf.

[27] R. B. Barr and J. Tagg, From teaching to learning: A new paradigm for undergraduate education, Change 27, 12 (1995).

[28] L. Shulman, Those who understand: Knowledge growth in teaching, Educ. Res. 15, 4 (1986).

[29] B. C. Bruce, S. P. Bruce, R. L. Conrad, and H.-J. Huang, University science students as curriculum planners, teachers, and role models in elementary school classrooms, J. Res. Sci. Teach. 34, 69 (1997).

[30] S. L. Thompson, A. Collins, V. Metzgar, M. D. Joeston, and V. Shepherd, Exploring graduate-level scientist's participation in a sustained K-12 teaching collaboration, School Sci. Math. 102, 254 (2002).

[31] Physics Education Teacher Coalition, http://www.phystec .org. 
[32] Association of Public and Land Grant Universities Science and Mathematics Teaching Imperative, http://www.aplu .org/projects-and-initiatives/stem-education/science-andmathematics-teaching-imperative/.

[33] K. Hinko and N. Finkelstein, NSF Award 1423496, Pathways: Measuring the Impact of Participation in Informal STEM Programming on University Students, 2014.

[34] M. Cole, The Fifth Dimension: An After-School Program Built on Diversity (Russell Sage Foundation, New York, 2006).

[35] R. Schwartz, Ph.D. thesis, Oregon State University, 2004.

[36] JILA NSF Physics Frontier Center for Atomic, Molecular, and Optical Physics, http://jila.colorado.edu/.

[37] R. Wulf, K. Hinko, and N. D. Finkelstein, in Proceedings of the 2012 Physics Education Research Conference, Philadelphia, PA (Ref. [6]), pp. 430-433.

[38] R. Wulf, K. Hinko, and N. D. Finkelstein, in Proceedings of the 2013 Physics Education Research Conference, Portland, OR (AIP, New York, 2013), pp. 369-372.

[39] L. Vygotsky, Mind in Society (Harvard University Press, Cambridge, MA, 1978), Chap. 7.

[40] K. Hinko, J. Seneca, and N. D. Finkelstein, in Proceedings of the 2014 Physics Education Research Conference, Minneapolis, MN (AIP, New York, 2014).

[41] M. Cole, Cultural Psychology: A Once and Future Discipline (Harvard University Press, Cambridge, MA, 1996).

[42] A. Leont'ev, Activity, Consciousness, and Personality (Prentice-Hall, Englewood Cliffs, NJ, 1978).
[43] V. V. Davydov and L. A. Radzikhovskii, Lev Vygotsky: Critical Assessments (Routledge, London, 1999), Vol. 1, p. 113.

[44] V. Kaptelinin and B. A. Nardi, Acting with Technology: Activity Theory and Interaction Design (MIT Press, Cambridge, MA, 2006), Chap. 3.

[45] I. Beatty and A. Feldman, Viewing teacher transformation through the lens of cultural-historical activity theory (CHAT), Educ. Change 16, 2 (2012).

[46] E. Price, C. De Leone, and N. Lasry, in Proceedings of the 2010 Physics Education Research Conference, Portland, OR (AIP, New York, 2010).

[47] H. Daniels, A. Edwards, Y. Engestrom, T. Gallagher, and S. Ludvigsen, Activity Theory in Practice: Promoting Learning across Boundaries and Agencies (Routledge, Abingdon, 2009).

[48] Y. Engestrom, Learning by Expanding: An ActivityTheoretical Approach to Developmental Research (Orienta-Konsultit, Helsinki, 1987).

[49] T. Patchen and D. Smithenry, Diversifying instruction and shifting authority: A cultural historical activity theory (CHAT) analysis of classroom participant structures, J. Res. Sci. Teach. 51, 606 (2014).

[50] See Supplemental Material at http://link.aps.org/ supplemental/10.1103/PhysRevPhysEducRes.12.010111 for video clips associated with the three main pedagogical modalities: instruction, consultation, and participation modes.

[51] B. T. Spike and N. Finkelstein, in Proceedings of the 2010 Physics Education Research Conference, Portland, OR (AIP, New York, 2010), pp. 309-312. 